\title{
Tumor growth activity of duloxetine in Ehrlich carcinoma in mice
}

\author{
Ed Carlos Rey Moura', Plinio da Cunha Leal', Izabel Cristina Portela Bogéa Serra', Bruno de Paulo Ribeiro', \\ Johnny Ramos do Nascimento ${ }^{1}$, Flavia Raquel Fernandes do Nascimento ${ }^{1}$ and Rioko Kimiko Sakata ${ }^{2 *}$
}

\begin{abstract}
Objective: The objective of this study was to analyze whether duloxetine influences tumor growth in Ehrlich carcinoma. The mice were administered 5 or $30 \mathrm{mg} / \mathrm{kg}$ of duloxetine or saline solution. All animals were inoculated with tumor cells. The tumor progression was evaluated by body weight, abdominal circumference, ascites volume and tumor cell count. The effect of duloxetine on immune response was evaluated by lymphoid cells, nitric oxide (NO) production, arginase and superoxide dismutase (SOD) activity and the spleen immunophenotyping.

Results: There was no difference between the groups regarding weight, abdominal circumference, ascites volume and number of tumor cells. Duloxetine increased the cells of the inguinal lymph node. There was no difference in the number of cells in the bone marrow and spleen. Ascites SOD activity was greater in Duloxetine groups. There were no differences in the levels of NO, nitrite, and arginase. The number of antibody for CD3 (CD3+), CD4+, CD8+ and CD28+ cells was lower in the duloxetine groups. In conclusion, duloxetine has no direct effect on tumor growth and does not alter immunity. The drug increased the SOD that fights free radicals and led the migration of lymphocytes, suggesting that duloxetine could be used in tumor-bearing individuals.
\end{abstract}

Keywords: Cancer, Duloxetine, Tumor growth

\section{Introduction}

Cancer pain is treated according to the analgesic ladder, with opioids on the second and third steps. Adjuvants, such as duloxetine, can be used in combination on all steps. The use of antidepressants is important to appropriately treat cancer pain. The study on the effect of adjuvants is important to select drugs that do not increase tumor growth.

In the Ehrlich's tumor, a mammary carcinoma of female mice in ascitic form, pain is caused by the inflammatory response, and pressure exerted by progressive tumor enlargement, hemorrhage, and neural compression [1].

Duloxetine would be an interesting analgesic drug for its anti-inflammatory effect [2]. Duloxetine is a reuptake inhibitor for serotonin (5-HT) and norepinephrine in the central nervous system that reduces pain transmission

\footnotetext{
*Correspondence: rsakata@unifesp.br

2 Universidade Federal de São Paulo, Rua Três de Maio 61/51, Vila Clementino, São Paulo, Brazil

Full list of author information is available at the end of the article
}

[3]. Duloxetine, in vitro, was able to decrease the viability of hepatocellular carcinoma cells [4].

There aren't any studies about the in vivo effect of duloxetine on the effect of duloxetine on the tumor progression and on the immune response.

The present study aimed to evaluate whether duloxetine directly influences tumor growth, in the Ehrlich's tumor model in mice.

\section{Main text}

Materials and methods

After approval from the Ethics Committee (CEUA 5923020415), 15 adult female Swiss mice, with 60 days and between 25 and $30 \mathrm{~g}$ were housed 5/cage on a 12-h-light/-dark cycle in a temperature-controlled room with food and water available ad libitum. Animal experiments were carried out in accordance with the International Association for the Study of Pain (IASP). Every effort was made to reduce the number of animals used and their discomfort.

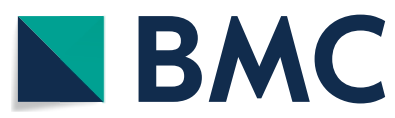

(c) The Author(s) 2018. This article is distributed under the terms of the Creative Commons Attribution 4.0 International License (http://creativecommons.org/licenses/by/4.0/), which permits unrestricted use, distribution, and reproduction in any medium, provided you give appropriate credit to the original author(s) and the source, provide a link to the Creative Commons license, and indicate if changes were made. The Creative Commons Public Domain Dedication waiver (http://creativecommons.org/ publicdomain/zero/1.0/) applies to the data made available in this article, unless otherwise stated. 
The mice were divided into three groups with 5 animals each. Groups D5 and D30 received 5 and $30 \mathrm{mg} / \mathrm{kg}$ of duloxetine, respectively; group $\mathrm{S}$ (control) received $0.2 \%$ of hydroxypropyl methylcellulose. On the first day, all animals received an intraperitoneal inoculation of $2 \times 10^{6}$ Ehrlich ascites carcinoma cells. From the second to the eighth day, duloxetine in $0.2 \%$ of hydroxypropyl methylcellulose or $0.2 \%$ hydroxypropyl methylcellulose was administered daily by gavage. All animals received the same volume $(10 \mathrm{~mL} / \mathrm{kg})$ and concentration of the vehicle. The animals were euthanized by lethal injection of $100 \mu \mathrm{L}$ of anesthetic drugs (2:1 solution of $10 \%$ ketamine and $20 \%$ xilasine hydrochloride, $100 \mathrm{uL}$ ) by intramuscular route.

Ehrlich's tumor is maintained in the Immunophysiology laboratory of UFMA, through weekly intraperitoneal transplantation of tumor cells $\left(2 \times 10^{6} / \mathrm{animal}\right)$ in healthy Swiss mice. To obtain the tumor cells, mice with approximately 7-day evolution of the Ehrlich ascites tumor are sacrificed, the ascites fluid collected from the peritoneal cavity, resuspended in centrifuged phosphate buffered solution and the cells are resuspended in $5 \mathrm{~mL}$ of phosphate buffered saline (PBS). To determine the concentration of tumor cells presents in this suspension, cells are counted in the Neubauer chamber, and cells viability is determined by the trypan blue exclusion test. Only suspensions with viability greater than $95 \%$ were used.

These were evaluated: weight and abdominal circumference both measured on the first and tenth day; volume of ascites; viable ascites tumor cells; number of cells of lymphoid organs (femur, spleen and inguinal lymph nodes), by optical microscopy; $\mathrm{NO}$ in the ascites and spleen, determined by nitrites, measured by colorimetric assay; arginase in ascites; SOD in ascites; and immunophenotyping of spleen.

The results were analyzed using Graph Pad Prism 5.0 ${ }^{\circledR}$. There was used the Kruskal-Wallis test to compare the groups. The level of significance considered was $\mathrm{p} \leq 0.05$.

\section{Results}

The treatment with Duloxetine has no effect on tumor development. There was no difference between the groups regarding weight, abdominal circumference, ascites volume and number of tumor cells (Table 1). Leukocyte concentration in the inguinal lymph node was higher in Duloxetine groups. The treatment with duloxetine had no effect on other lymphoid organs; there was no difference in the number of cells in the bone marrow and spleen (Table 1).

Both Duloxetine groups increased SOD activity in ascites (Table 2).There were no differences in the levels of NO, nitrite and arginase between groups (Table 2).

Duloxetine treatment decreased T lymphocyte number and its activation; the absolute number of CD3+ lymphocytes was lower in duloxetine groups. There was no difference in the absolute frequency of activated CD4+ and CD8+ lymphocytes between groups. Finally, the expression of the costimulatory molecule CD28 in both $\mathrm{T}$ helper lymphocyte (T CD4) and cytotoxic T lymphocyte (T CD8) lymphocytes was lower in the Duloxetine groups (Table 3 ).

There was listed the information about Additional material, with file name, title of data and description of data at the section Additional file 1.

\section{Discussion}

In this study, it was found that duloxetine does not show a harmful role in tumor growth and proliferation, but it caused a significant reduction in the number of spleen $\mathrm{T}$ lymphocytes, and in its activation, as evidenced by immunophenotyping, as well as increased SOD activity, suggesting a reduction in the inflammatory response in the tumor-bearing mice.

The action of duloxetine on tumor growth was studied given that it is important to use adjuvants that do not exacerbate tumor growth. Adjuvants with fewer negative effects on tumor dissemination should be chosen,

Table 1 Weight, volume of ascites, abdominal circumference, tumor cells, and leukocytes (median/IQR)

\begin{tabular}{|c|c|c|c|c|}
\hline & D5 & D30 & $\mathrm{S}$ & $\mathbf{p}$ \\
\hline Weight (g) & $41(37.5-41.5)$ & $41(34-44)$ & $34(32.5-39.5)$ & 0.160 \\
\hline Ascites V (mL) & $8.2(5-8.6)$ & $8(6.0-8.3)$ & $6.2(3.3-7.1)$ & 0.140 \\
\hline Circumference (cm) & $10(9.5-10.2)$ & $10.5(9.7-11.2)$ & $9.5(8.5-10.4)$ & 0.216 \\
\hline Living tumor cel. $\left(\times 10^{6} / \mathrm{mL}\right)$ & $390(272-502)$ & $375(280-607)$ & $472(265-516)$ & 0.887 \\
\hline Leukocytes $\left(\times 10^{8} / \mathrm{mL}\right)$ Spleen & $2500(1813-3313)$ & $2000(1250-2375)$ & $2300(1325-3700)$ & 0.509 \\
\hline $\mathrm{IL}$ & $240(167-682)^{*}$ & $135(130-190)^{*}$ & $85(65-142)$ & 0.015 \\
\hline $\mathrm{BN}$ & $600(412-815)$ & $995(617-1005)$ & $510(440-667)$ & 0.112 \\
\hline
\end{tabular}

$D 55 \mathrm{mg} / \mathrm{kg}, D 30$ duloxetine $30 \mathrm{mg} / \mathrm{kg}$, S saline, $V$ volume, Cel cells, ML mesenteric lymph nodes, IL inguinal lymph node, BN bone narrow, Kruskal-Wallis test, IQR interquartile

*Significant 
Table 2 Effect of Duloxetine treatment on concentration of NO, nitrite, arginase and SOD activity from Ehrlich tumorbearing mice

\begin{tabular}{lcccc}
\hline & D5 & D30 & C & p \\
\hline Spleen NO (mM) & $3.5(2.5-4.5)$ & $6.4(3.1-10.0)$ & $1.6(0.8-4.0)$ & 0.080 \\
Ascites NO (mM) & $13.9(11.4-16.7)$ & $12.7(7.0-19.6)$ & $12.6(11.2-18.3)$ & 0.801 \\
Ascites nitrite (mM) & $5.1(4.9-7.1)$ & $5.0(4.6-5.6)$ & $5.4(4.9-5.6)$ & 0.499 \\
Ascites arginase (unit/L) & $48.6(45.8-51.4)$ & $52.9(45.5-56.7)$ & $48.1(36.7-67.7)$ & 0.690 \\
Ascites SOD (\% activity) & $92.5(88.9-96.9)^{*}$ & $91.6(87.7-94.2)^{*}$ & $87.6(86.5-88.4)$ & 0.050 \\
\hline
\end{tabular}

The animals were treated with duloxetine $\left(5\right.$ and $30 \mathrm{mg} / \mathrm{kg}$ ) or saline (control) orally from days 2 to 8 after intraperitoneal inoculation of the $2 \times 10^{6}$ Ehrlich tumor cells (median/IQR)

$D 55 \mathrm{mg} / \mathrm{kg}$, D30 duloxetine $30 \mathrm{mg} / \mathrm{kg} ;$ S saline, NO nitric oxide, SOD superoxide dismutase, Kruskal-Wallis test, IQR interquartile

*Significant

Table 3 Immunophenotyping of spleen (median/IQR)

\begin{tabular}{lllll}
\hline & D5 & D30 & S & p \\
\hline $\mathrm{CD} 3\left(\times 10^{7} / \mathrm{mL}\right)^{\mathrm{a}}$ & $1.0(0.7-1.4)^{*}$ & $1.3(1.1-1.6)^{*}$ & $2.2(1.2-2.4)$ & 0.045 \\
$\mathrm{CD} 4\left(\times 10^{7} / \mathrm{mL}\right)^{\mathrm{a}}$ & $0.7(0.5-0.9)$ & $0.8(0.6-0.9)$ & $1.5(1.0-1.7)$ & 0.2448 \\
$\mathrm{CD} 8\left(\times 10^{7} / \mathrm{mL}\right)^{\mathrm{a}}$ & $0.2(0.1-0.2)$ & $0.3(0.2-0.5)$ & $0.4(0.2-0.5)$ & 0.088 \\
$\mathrm{CD} 28\left(\times 10^{5} / \mathrm{mL}\right)^{\mathrm{b}}$ & $39(37-40)^{*}$ & $42(39-45)^{*}$ & $51(45-52)$ & 0.010 \\
\hline
\end{tabular}

D5 $5 \mathrm{mg} / \mathrm{kg}$, D30 duloxetine $30 \mathrm{mg} / \mathrm{kg}$, S saline

a Absolute frequency of spleen lymphocytes

${ }^{b}$ Fluorescence intensity of spleen lymphocytes; Kruskal-Wallis test; IQR interquartile

*Significant

and one study suggested that duloxetine inhibits tumor growth [4]. Duloxetine in doses of 5 and $30 \mathrm{mg} / \mathrm{kg}$ was administered based on the experimental literature $[5,6]$.

Pain results in the release of cytokines and reduces immunity, so pain control is extremely relevant. Good pain control results in a reduction in the tumor metastasis [7].

Tumor inoculation was similar in the Fernandes et al. [8] with the same number of tumor cells as in Patra et al. [9].

Immunophenotyping of the spleen was performed given that it is a site of great accumulation of defense cells. NO is degraded generating nitrite, so nitrite indirectly measures NO production [10]. Duloxetine reduced, though not significantly, the concentration of nitrite. The role of NO is twofold: it promotes tumor dissemination and is also tumoricidal [11]. At lower concentrations $(<100 \mathrm{nM}), \mathrm{NO}$ causes tumor progression [11] and at higher concentrations $(>100 \mathrm{nM})$, it induces apoptosis [12]. NO can promote tumor growth at the concentration measured. Arginine metabolism is important for reducing cell death [13]. Increased arginase activity, related to tumor growth, decreases the production of NO [14].

Tumor growth is associated with the reduction of SOD activity $[9,12])$. SOD activity increased with duloxetine as well as in another study [15]. SOD protects cells from damage [16].

After assessing the tumor microenvironment (dosage of NO, arginase, nitrite and SOD) we decided to evaluate whether duloxetine influences the immune system. Therefore, we evaluated their cellular impact, quantifying the $T$ lymphocytes in the spleen.

The number of $\mathrm{T}$ lymphocytes stained with the $\mathrm{CD} 3$ antibody (CD4+ $\mathrm{T}$ and $\mathrm{CD} 8+\mathrm{T}$ cells) was lower with duloxetine. CD4+ and CD8+ T lymphocytes destroy tumor cells [17]. In addition, there was a lower number of $\mathrm{CD} 4+$ and CD8+ T cells expressing the CD28 receptor with duloxetine. CD28 hinders cellular energy production [18].

As the cells were activated and had a decrease in the spleen it was assumed that the lymphocytes, when activated, migrated from the spleen to other sites, such as inguinal lymph nodes. Hofstetter et al. [19] also observed this effect on lymphocytes when they studied the influence of 5-HT reuptake inhibitor drugs on the immunity.

In conclusion, duloxetine has no direct effect on tumor growth and does not alter immunity. The drug increased the SOD that fights free radicals and led to the migration of lymphocytes, such as other drugs of its group. Due to its analgesic effect, Duloxetine can be regarded as an adjuvant option for cancer pain management.

\section{Limitations}

The results obtained in animals cannot be directly generalized to humans, and the results may vary with different tumor types. Future studies may show whether the data can be extrapolated to humans. However, as aforementioned, this is the first study investigating whether this drug may worsen tumors.

\section{Additional file}

Additional file 1. Additional tables. 


\section{Abbreviations}

5-HT: serotonin; CD3: antibody for CD3; D: duloxetine; IASP: International Association for the Study of Pain; NO: nitric oxide; PBS: phosphate buffered saline; SOD: superoxide dismutase; T CD4+: Thelper lymphocyte; T CD8+: cytotoxic T lymphocyte; UFMA: Universidade Federal do Maranhão.

\section{Authors' contributions}

ECRM: Data collection, study conception and designing, data analysis, article writing. PCL: Article writing, data analysis and interpretation. ICPBS: Data collection, study design, data analysis. BPR: Data analysis. JRN: Data analysis. FRFN: Data analysis. RKS: Study conception and design, article writing, critical revision of the intellectual content. All authors read and approved the final manuscript.

\section{Author details}

${ }^{1}$ Universidade Federal do Maranhão, São Luís, Brazil. ${ }^{2}$ Universidade Federal de São Paulo, Rua Três de Maio 61/51, Vila Clementino, São Paulo, Brazil.

\section{Acknowledgements}

Coordination of Improvement of Higher Education Personnel (CAPES).

\section{Competing interests}

The authors declare that they have no competing interests

\section{Availability of data and materials}

At Universidade Federal do Maranhão. Data from animals and evaluation was sent as additional files.

\section{Consent to publish}

Not applicable.

\section{Ethics approval and consent to participate}

Ethics Committee of Universidade Federal do Maranhão.

\section{Funding}

This study was funded by Conselho Nacional de Desenvolvimento Científico e Tecnológico (CNPq) (Grant No 305608/2015-0, http://www.cnpq.br) to Flávia Raquel Fernandes do Nascimento. The funder had no role in study design, data collection and analysis, decision to publish, or preparation of the manuscript.

\section{Publisher's Note}

Springer Nature remains neutral with regard to jurisdictional claims in published maps and institutional affiliations.

Received: 7 June 2018 Accepted: 26 July 2018

Published online: 31 July 2018

\section{References}

1. Calixto-Campos C, Zarpelon AC, Corrêa M, Cardoso RD, Pinho-Ribeiro FA, Cecchini R, et al. The Ehrlich tumor induces pain-like behavior in mice: a novel model of cancer pain for pathophysiological studies and pharmacological screening. Biomed Res Int. 2013;2013:624815. https:// doi.org/10.1155/2013/624815 (Epub 2013 Aug 29).

2. Jones CK, Peters SC, Shannon HE. Efficacy of duloxetine, a potent and balanced serotonergic and noradrenergic reuptake inhibitor, in inflammatory and acute pain models in rodents. J Pharmacol Exp Ther. $2005 ; 312(2): 726-32$
3. Irving G, Tanenberg RJ, Raskin J, Risser RC, Malcolm S. Comparative safety and tolerability of duloxetine vs. pregabalin vs. duloxetine plus gabapentin in patients with diabetic peripheral neuropathic pain. Int J Clin Pract. 2014;68(9):1130-40. https://doi.org/10.1111/ijcp.12452 Epub 2014 May 18

4. Kuwahara J, Yamada T, Egashira N, Ueda M, Zukeyama N, Ushio S, et al. Comparison of the anti-tumor effects of selective serotonin reuptake inhibitors as well as serotonin and norepinephrine reuptake inhibitors in human hepatocellular carcinoma cells. Biol Pharm Bull. 2015;38(9):1410-4.

5. Joshi SK, Hernandez G, Mikusa JP, et al. Comparison of antinociceptive actions of standard analgesics in attenuating capsaicin and nerve-injuryinduced mechanical hypersensitivity. Neuroscience. 2006;143(2):587-96.

6. Munro G. Pharmacological assessment of the rat formalin testutilizing the clinically used analgesic drugs gabapentin, lamotrigine, morphine. duloxetine, tramadol and ibuprofen: influence of low and high formalin concentrations. Eur J Pharmacol. 2009;605(1-3):95-102.

7. Fodale V, D'Arrigo MG, Triolo S, Mondello S, La Torre D. Anesthetic techniques and cancer recurrence after surgery. Sci World J. 2014:2014:328513. https://doi.org/10.1155/2014/328513.

8. Fernandes PD, Guerra FS, Sales NM, Sardella TB, Jancar S, Neves JS. Characterization of the inflammatory response during Ehrlich ascitic tumor development. J Pharmacol Toxicol Methods. 2015;71:83-9.

9. Patra S, Muthuraman MS, Prabhu AR, Priyadharshini RR, Parthiban S. Evaluation of antitumor and antioxidant activity of Sargassum tenerrimum against Ehrlich ascites carcinoma in mice. Asian Pac J Cancer Prev. 2015;16(3):915-21.

10. Deryagina VP, Ryzhova NI, Golubkina NA. Production of nitrogen oxide derivatives under the influence of NO-synthase inhibitors and natural compounds in mice with transplanted tumors. Exp Oncol. 2012;34(1):29-33.

11. Vahora H, Khan MA, Alalami U, Hussain A. The potential role of nitric oxide in halting cancer progression through chemoprevention. J Cancer Prev. 2016;21(1):1-12.

12. Alam B, Majumder R, Akter S, Lee SH. Piper betle extracts exhibit antitumor activity by augmenting antioxidant potential. Oncol Lett. 2015;9(2):863-8.

13. Bera S, Wallimann T, Ray S, Ray M. Enzymes of creatine biosynthesis, arginine and methionine metabolism in normal and malignant cells. FEBS J. 2008;275(23):5899-909.

14. Weinberg JB, Lopansri BK, Mwaikambo E, Granger DL. Arginine, nitric oxide, carbon monoxide, and endothelial function in severe malaria. Curr Opin Infect Dis. 2008;21(5):468-75.

15. Salat K, Moniczewski A, Librowski T. Nitrogen, oxygen or sulfur containing heterocyclic compounds as analgesic drugs used as modulators of the nitroxidative stress. Mini Rev Med Chem. 2013;13(3):335-52.

16. Huang P, Feng L, Oldham EA, Keating MJ, Plunkett W. Superoxide dismutase as a target for the selective killing of cancer cells. Nature. 2000;407(6802):390-5.

17. Vesely MD, Kershaw MH, Schreiber RD, Smyth MJ. Natural innate and adaptive immunity to cancer. Ann Rev Immunol. 2011;29:235-71.

18. Manzotti CN, Liu MK, Burke F, Dussably L, Zheng Y, Sansom DM. Integration of CD28 and CTLA-4 function results in differential responses of T cells to CD80 and CD86. Eur J Immunol. 2006;36(6):1413-22.

19. Hofstetter HH, Mössner R, Lesch KP, Linker RA, Toyka KV, Gold R. Absence of reuptake of serotonin influences susceptibility to clinical autoimmune disease and neuroantigen-specific interferon-gamma production in mouse EAE. Clin Exp Immunol. 2005;142(1):39-44. 